\title{
ADJEKTIVA BAHASA NGALUM
}

\section{ADJEKTIVE OF NGALUM LANGUAGE}

\author{
Siti Masitha Iribaram \\ Balai Bahasa Provinsi Papua dan Provinsi Papua Barat \\ Jalan Yoka, Waena, Distrik Heram, Kota Jayapura, Papua \\ Pos-el: sitha.iribaram@yahoo.com \\ Telepon 081344074515
}

\begin{abstract}
Abstrak
Salah satu bahasa daerah yang terdapat di Provinsi Papua dengan jumlah penutur yang banyak adalah bahasa Ngalum. Bahasa Ngalum dituturkan oleh masyarakat suku Ngalum yang tinggal di Lembah Oksibil, Okisop, dan Okbon, Kabupaten Pegunungan Bintang. Seperti halnya bahasabahasa lain di dunia, bahasa Ngalum terdiri atas beberapa kelas kata. Salah satu di antaranya adalah adjektiva. Dalam artikel ini, adjektiva bahasa Ngalum didasarkan pada adjektiva bahasa Indonesia dari segi perilaku semantisnya. Tulisan ini mengunakan metode deskriptif dengan tiga tahapan, yaitu tahap penyediaan data, tahap analisis data, dan tahap penyajian hasil analisis data. Penyediaan data tulisan ini menggunakan metode cakap dengan teknik pancing sebagai teknik dasar dan teknik cakap semuka serta teknik catat sebagai teknik lanjutan. Analisis data menggunakan metode distribusional. Ada dua tipe pokok adjektiva, yaitu adjektiva bertaraf yang mengungkapkan suatu kualitas mencakupi (1) adjektiva pemeri sifat, (2) adjektiva ukuran, (3) adjektiva warna, (4) adjektiva waktu, (5) adjektiva jarak, (6) adjektiva sikap batin, dan (7) adjektiva cerapan dan adjektiva tak bertaraf yang mengungkapkan keanggotaan dalam suatu golongan.
\end{abstract}

Kata kunci: adjektiva, bertaraf, dan tak bertaraf

\begin{abstract}
Ngalum language is one of local language whose large native speaker in Papua Province. Ngalum language is spoken by Ngalum tribes who live in Oksibil valley, Okisop valley, and Okbon valley of Pegunungan Bintang Regency. Ngalum language has some word classes as like other languages in the world. One of them is adjective. In this article, adjective of Ngalum language is based on adjective of Bahasa Indonesia from its semantical behavior. This writing used three stages of descriptive method. They are, collecting data stage, analyzing data stage and presenting the result of the data analysis. Data, in this writing, was collected using interview method (metode cakap) through stimulation technique (teknik pancing) as a basic technique while face-to-face interview (cakap semuka) and noting technique (teknik catat) as advanced techniques. Thus, data analyzing used distributional method. There are two main types of adjective, namely, adjective of quality and adjective of quantity. Adjective of quality, which explores about quality of a noun, consist of (1) opinion as adjective, (2) size as adjective, (3) colour as adjective, (4) timelage as adjective, (5) space as adjective, (6) feeling as adjective, and (7) sense as adjective. While, adjective of quantity explores about a membership of a noun in a group.
\end{abstract}

Keywords: adjective, quality and quantity. 


\section{Pendahuluan}

Wilayah Papua memiliki bahasa-bahasa daerah dan suku-suku bangsa yang terbanyak jumlahnya di negara kita. Tiap-tiap suku dan kelompok etnik itu mempunyai kebudayaan sendiri, termasuk bahasanya. Menurut data Summer Institute of Linguistic (2006), jumlah bahasa daerah di Indonesia sekitar 742 bahasa, sebanyak 271 ada di Papua. Sementara Badan Pengembangan dan Pembinaan Bahasa dahulu Pusat Bahasa (2013), jumlah bahasa daerah di Provinsi Papua dan Provinsi Papua Barat sebanyak 307. Jumlah itu hanyalah hasil inventarisasi sementara, sebab beberapa daerah sampai saat ini belum terjangkau oleh orang luar. Keadaan bahasa daerah tersebut sebagian jumlah penuturnya kecil. Salah satu bahasa daerah yang terdapat di Provinsi Papua dengan jumlah penutur yang banyak adalah bahasa Ngalum. Oleh karena itu, pola pelestarian bahasa di Tanah Papua sangat penting dan mendesak.

Menurut SIL (2006:50) penutur bahasa Ngalum diperkirakan 18.000 orang. Bahasa Ngalum dituturkan oleh masyarakat suku Ngalum yang tinggal di Lembah Oksibil, Okisop, dan Okbon, Kabupaten Pegunungan Bintang, Provinsi Papua. Bahasa Ngalum juga dituturkan oleh masyarakat wilayah perbatasan di pegunungan utama wilayah bahasa Muyu (Yongkom) sebelah utara dan Iwur, Nakai sebelah timur laut, dan di Papua Nugini. Bahasa Ngalum termasuk dalam klasifikasi kelas Trans-Nugini, bagian utara, tengah, dan barat, Nugini tengah dan selatanKutubuan, Nugini tengah dan selatan, Ok, dan Mountain. Bahasa Ngalum memiliki tiga dialek, yaitu (1) dialek Ngalum, (2) dialek Apmisibil, dan (3) dialek Sibil.

Belum banyak tulisan yang membahas bahasa Ngalum. Tahun 2015, tim peneliti Balai Bahasa Provinsi Papua sedang meneliti fonologi bahasa Ngalum yang bertujuan mendokumentasikan kosakata bahasa Ngalum. Dari hasil penelitian dan tulisan tentang bahasa Ngalum, diketahui bahwa belum ada yang membahas tentang adjektiva.
Seperti halnya dengan bahasa-bahasa lain yang ada di dunia, bahasa Ngalum terdiri atas beberapa kelas kata. Salah satu di antaranya adalah adjektiva. Adjektiva merupakan salah satu kelas kata utama di dalam semua bahasa maka dipandang perlu untuk mengetahui adjektiva bahasa daerah termasuk adjektiva bahasa Ngalum.

Tulisan ini bertujuan untuk mendeskripsikan adjektiva bahasa Ngalum yang meliputi adjektiva bertaraf dan adjektiva tak bertaraf secara semantis.

\section{Landasan Teori}

Adjektiva sebagai kelas kata utama pada setiap bahasa selalu menjadi pembicaraan ahli-ahli bahasa. Menurut Alwi dkk. (2003:171) adjektiva adalah kata yang memberikan keterangan yang lebih khusus tentang sesuatu yang dinyatakan oleh nomina dalam kalimat. Adjektiva yang memberikan keterangan terhadap nomina itu berfungsi atributif. Keterangan itu dapat mengungkapkan suatu kualitas atau keanggotaan dalam suatu golongan. Selanjutnya adjektiva juga dapat berfungsi sebagi predikat dan adverbial kalimat. Fungsi predikat dan adverbial dapat mengacu ke suatu keadaan. Adjektiva juga dicirikan oleh kemungkinannya menyatakan tingkat kualitas dan tingkat bandingan acuan nomina yang diterangkannya. Perbedaan tingkat kualitas ditegaskan dengan pemakaian kata seperti sangat dan agak di samping adjektiva.

Menurut Chaer (2000:103) kata-kata yang dapat diikuti dengan kata keterangan sekali serta dapat dibentuk menjadi kata ulang berimbuhan SE-NYA disebut kata sifat atau adjektiva. Selain itu, Kridalaksana (2005:59) mengatakan bahwa adjektiva adalah kategori yang ditandai oleh kemungkinan untuk (1) bergabung dengan partikel tidak, (2) mendampingi nomina, atau (3) didampingi partikel seperti lebih, sangat, agak, mempunyai ciri-ciri morfologis, atau (5) dibentuk menjadi nomina dengan konfiks kean.

Dari segi bentuk, adjektiva dasar sukar dibedakan dengan verba dasar atau nomina dasar. Oleh karena itu, klasifikasi 
adjektiva akan dipaparkan berdasarkan ciri semantisnya. Kelas adjektiva menunjukkan adanya dua tipe pokok, yaitu adjektiva bertaraf yang mengungkapkan suatu kualitas dan adjektiva tak bertaraf yang mengungkapkan keanggotaan dalam suatu golongan. Pembedaan adjektiva yang bertaraf dari adjektiva yang tak bertaraf bertalian dengan mungkin tidaknya adjektiva itu menyatakan berbagai tingkat kualitas dan berbagai tingkat bandingan. Untuk maksud itu dapat dipakai kata seperti sangat, agak, lebih, dan paling. Adjektiva tak bertaraf, sebaliknya, tidak dapat diberi pewatas tersebut. Dalam artikel ini, yang akan dibahas adalah adjektiva bahasa Ngalum berdasarkan perilaku semantisnya.

\section{Metode Penelitian}

Penelitian ini menggunakana tiga tahapan strategis yang dilakukan secara beruntun. Ketiga tahapan tersebut adalah tahap penyediaan data, tahap penganalisisan data, dan tahap penyajian hasil analisis data (Sudaryanto, 1993:5).

Penyediaan data penelitian ini menggunakan metode cakap dengan teknik pancing sebagai teknik dasar dan teknik cakap semuka serta teknik catat sebagai teknik lanjutan (Sudaryanto, 1993:137-139). Sementara itu, analisis data menggunakan metode distribusional dengan teknik bagi unsur langsung sebagai teknik dasar dan teknik lesap, teknik pindah, dan teknik sisip sebagai teknik lanjutan (Sudaryanto, 1993:31-71). Setelah data dianalisis hasilnya disajikan dengan metode formal (Sudaryanto, 1993:145).

\section{Pembahasan}

Untuk mengetahui adjektiva dalam bahasa Ngalum digunakan jenis-jenis adjektiva bahasa Indonesia dari segi perilaku semantisnya yang dibedakan atas adjektiva bertaraf dan adjektiva tak bertaraf. Selain itu, akan dikemukakan juga adjektiva bentuk, adjektiva yang menunjukkan cacat tubuh, dan perulangan adjektiva.

\subsection{Adjektiva Bertaraf dalam Bahasa Ngalum}

Berdasarkan analisis data, dapat diketahui bahwa adjektiva bertaraf dalam bahasa Ngalum meliputi (1) adjektiva pemeri sifat, (2) adjektiva ukuran, (3) adjektiva warna, (4) adjektiva waktu, (5) adjektiva jarak, (6) adjektiva sikap batin, dan (7) adjektiva cerapan. Secara semantis batas di antara tujuh kategori itu tidak selalu jelas, bahkan kadangkadang bertumpang tindih.

4.1.1 Adjektiva Pemeri Sifat Bahasa Ngalum Adjektiva pemeri sifat jenis ini dapat memerikan kualitas dan intensitas yang bercorak fisik atau mental. Dalam bahasa Ngalum dapat ditemukan adanya adjektiva pemeri sifat. Untuk lebih jelasnya akan dikemukakan beberapa contoh sebagai berikut.
(1) уертит
(2) walkol
(3) mamin
(4) ngil
(5) уертит

Dalam kontruksi kalimat, adjektiva pemeri sifat bahasa Ngalum diilustrasikan seperti pada contoh di bawah ini.

(1)abipa pelaka puka yepmum rumah halaman itu bersih 'halaman rumah itu bersih'

(2) ok peka walkol sungai sini dangkal 'sungai di sini dangkal'

(3) abenung pedingaka mamin cuaca hari ini panas 'cuaca hari ini panas'

(4)ok wol peka abenong Oksibil ngil sungai air ini Kampung Oksibil dingin

'air sungai di Kampung Oksibil dingin'

\section{(5)abenong peka pe yepmum kampung ini suasana aman 'suasana kampung ini aman'}




\subsubsection{Adjektiva Ukuran Bahasa Ngalum}

Adjektiva ukuran mengacu ke kualitas yang dapat diukur dengan ukuran yang sifatnya kuantitatif. Dalam bahasa Ngalum dapat ditemukan adanya adjektiva ukuran. Untuk lebih jelasnya akan dikemukakan pada contoh berikut ini.
(1)kukun
(2)pong
(3) simit
(4) murup
(5) dalo
'pendek'
'berat'
'ringan'
'tinggi'
'luas'

Dalam kontruksi kalimat, adjektiva ukuran bahasa Ngalum diilustrasikan seperti pada contoh di bawah ini.

(1)ade puka kukun kayu itu berat

'kayu itu berat'

(2)nanung mena pongki burabor

ibu tas ringan bawa

'ibu membawa tas yang ringan'

(3) sino ninga ade simitki puka nginwanser

kemarin adik pohon tinggi itu panjat

'kemarin adik memanjat pohon yang tinggi itu'

(4)ade darik puka murup pohon jambu itu pendek 'pohon jambu itu masih'

(5)botom yongapa dalo bapak milik kebun luas 'bapak memiliki kebun yang luas'

\subsubsection{Adjektiva Warna Bahasa Ngalum}

Dalam bahasa Ngalum, adjektiva warna mengacu ke berbagai warna. Penutur bahasa Ngalum lebih banyak mengenal warna dasar. Selain itu, penutur bahasa Ngalum juga mengenal warna yang diambil dari nama buah dan bagian tubuh. Untuk lebih jelasnya akan dikemukakan contoh berikut ini.
(1) woki
'merah'
(2)birki
'hitam'
(3) kutki
'putih'
(4)yakpok
'kuning'
(5) akonpap
'hijau'

Dalam kontruksi kalimat, adjektiva warna bahasa Ngalum diilustrasikan seperti pada contoh di bawah ini.
(1)neya opkal woki ngulburkosir saya baju merah memakai 'saya memakai baju warna merah'
(2)men birkiya sakomkiya ninga daretkoser

noken hitam milik nenek adik disobek 'noken hitam nenek disobek adik'

(3)nanong opkalapa yepkiya woki ibu baju baru putih 'baju baru ibu warna putih'

(4) uwa abol nongdarkadura yakpoki dia ikat kepala memakai kuning 'dia memakai ikat kepala warna kuning'

(5)ade wisol puka akonpap pohon daun itu hijau 'daun pohon itu semakin hijau'

\subsubsection{Adjektiva Waktu Bahasa Ngalum}

Adjektiva waktu mengacu ke masa proses, perbuatan, atau keadaan berada atau berlangsung sebagai pewatas. Adjektiva waktu terdapat dalam bahasa Ngalum, tetapi tidak produktif. Untuk lebih jelasnya akan dikemukakan pada contoh berikut.
(1) using
'lama'
(2)dano
'cepat'
(3) dingper 'sering'
(4)pamtan
'lambat'
(5) dingper 'jarang'

Dalam kontruksi kalimat, adjektiva waktu bahasa Ngalum diilustrasikan seperti pada contoh di bawah ini.

(1)neya using tan mesemer pema saya lama sudah tunggu di sini 'saya sudah lama menunggu di sini'

\section{(2) uropa kanga dano nganar kakak babi cepat tangkap}


'kakak menangkap babi dengan cepat'

(3) eya dingper bilendaklon mum

dia sering berkelahi

'dia sering berkelahi'

(4)eya darowa etapamtan

dia pulang lambat

'dia biasa pulang lambat'

(5)eya dingper uma abibpa abomar dia jarang datang rumah ke 'dia jarang datang ke rumah'

\subsubsection{Adjektiva Jarak Bahasa Ngalum}

Dalam bahasa Ngalum, adjektiva jarak mengacu ke ruang antara dua benda, tempat, atau maujud sebagai pewatas nomina. Untuk lebih jelasnya dapat dilihat pada contoh berikut.
(1) kam
'jauh'
(2)dalo/ngekneder
'lebat'
(3) mep
'rapat'
(4)yерtanтum
'akrab'
(5) mep
'dekat'

Dalam kontruksi kalimat, adjektiva jarak bahasa Ngalum diilustrasikan seperti pada contoh di bawah ini.

(1) nuwa abibpapa gereja sona kam kami milik rumah gereja dari jauh 'rumah kami jauh dari gereja'

(2)abenong walapa ngekneder hutan di sana lebat 'hutan di sana lebat'

(3)bonengnonga mirona mepmepa do betatas tanam dekat-dekat jangan 'betatas jangan ditanam terlalu rapat'

(4)puwenga simin siripuka yeptanmum simin sirip

pertemuan dalam itu akrab suasana

'pertemuan itu dalam suasana yang akrab’

(5)bayenona mep pema tinggalnya dekat dari sini

'tinggalnya dekat dari sini'

\subsubsection{Adjektiva Sikap Batin Bahasa Ngalum} Adjektiva sikap batin bertalian dengan pengacuan suasana hati dan perasaan. Adjektiva sikap batin ini terdapat juga dalam bahasa Ngalum. Untuk lebih jelasnya dapat dilihat dari contoh berikut.
(1) ditparon
'bahagia'
(2) angankulon
'benci'
(3) atul
'jahat'
(4) yol
'sakit'
(5) podakandon
'takut'

Dalam kontruksi kalimat, adjektiva sikap batin bahasa Ngalum diilustrasikan seperti pada contoh di bawah ini.

(1)nanong ditparon ningkiya dakansur ibu bahagia adik ketemu 'ibu merasa bahagia ketemu adik'

(2)neyana angan kasemer saya benci dia 'saya benci dia'

(3)kakaki puka atul momki numarki tena pukona

milik orang itu jahat kepada anak dia 'orang itu jahat kepada anaknya'

(4)eya sinowa eya benser yol nek dia kemarin tidak datang sakit karena 'dia kemarin tidak datang karena sakit'

(5)neya nekel mumnek podakando ewabensir saya sendirian takut pulang 'saya takut pulang sendirian'

\subsubsection{Adjektiva Cerapan Bahasa Ngalum}

Adjektiva cerapan bertalian dengan pancaindera, yakni penglihatan, pendengaran, penciuman atau penghidungan, perabaan, dan pencitarasaan. Adjektiva cerapan dalam 
bahasa Ngalum akan dikemukakan pada contoh berikut.
(1) piyam
'terang'
(2)yepki
'nyaring'
(3) ulbom
'busuk'
(4)yepmin
'harum'
(5)mutar
(6) sitmol
(7) yep
(8)yep
'basah'
'licin'
'manis'
'enak'

Dalam kontruksi kalimat, adjektiva cerapan bahasa Ngalum diilustrasikan seperti pada contoh di bawah ini.

(1)alup peka piyam yep lampu ini terang baik 'lampu ini menyala terang'

(2)eya wenga dalotan kak yepki dia teriak keras suara nyaring 'dia berteriak dengan suara yang nyaring'

(3) anon peka ulbom neser anjing ini busuk bau 'anjing ini bau busuk'

(4)puwaset puka yepmin neser bunga itu harum bau 'bunga itu bau harum'

(5)eya opkala amok mutkoser dia baju hujan kena basah 'bajunya basah kena hujan'

(6)eya dae anser wola sitmol dia jatuh jalan licin 'dia jatuh karena jalanan licin'

(7)alop puka dito yep buah itu rasanya manis 'buah itu manis rasanya'

(8)enonmina peka dito yep makanan ini rasanya enak 'makanan ini enak rasanya'

\subsection{Adjektiva Tak Bertaraf Bahasa} Ngalum

Adjektiva tak bertaraf menempatkan acuan nomina yang diwatasinya di dalam kelompok atau golongan tertentu. Kehadirannya di dalam lingkungan itu tidak dapat bertaraftaraf. Sesuatu ada di dalamnya atau di luarnya. Termasuk di dalam kelompok ini adalah adjektiva bentuk. Adjektiva tak bertaraf yang terdapat dalam bahasa Ngalum adalah adjektiva bentuk dan adjektiva yang menunjukkan cacat tubuh. Untuk lebih jelasnya akan dikemukakan pada contoh berikut.
(1) tutun
'lurus'
(2) merep
'bengkok'
(3) murup
'bulat'
(4) pil
(5) sirop
'runcing'
'buta'
(6) dender
'lumpuh'

Dalam kontruksi kalimat, adjektiva tak bertaraf bahasa Ngalum diilustrasikan seperti pada contoh di bawah ini.

(1)ade apkulol peka tutunki pohon batang ini lurus 'batang pohon ini lurus'

(2) kutepa korkiya murup tungku ibu milik bulat 'tungku ibu bulat'

(3) ade apkulol puka merepki pohon batang itu bengkok 'batang pohon itu bengkok'

(4)botoma silmona pakor pareser
pilkiya puka
bapak anak panah patah yang sudah jadi runcing itu runcing itu' 'bapak mematahkan anak panah yang

(5)putenaka paron tanmum siropneder anak itu dari lahir buta 'anak itu buta sejak lahir' 
(6) urop yonaka

yonadendera mamentan dender

kakak kaki dia lumpuh panas

mati

'kaki kakak lumpuh setelah panas yang tinggi'

\subsection{Perulangan Adjektiva Bahasa Ngalum}

Kebanyakan adjektiva bahasa Ngalum adalah morfofonemis, artinya terdiri atas satu morfem. Namun, ada pula adjektiva bahasa Ngalum yang lebih dari satu morfem dan karena itu disebut polimorfemis. Adjektiva bahasa Ngalum yang polimorfemis dibentuk dengan cara perulangan sebagian, tetapi kata yang diulang itu pun telah memiliki status sebagai adjektiva. Untuk lebih jelasnya akan dikemukakan pada contoh berikut.
(1) sikbit-sikbitki 'tinggi-tinggi'
(2)talo-taloki
'besar-besar'
(3)yep-yepki 'cantik-cantik'
(4)ngorbor-ngorborki 'kurus-kurus'
(5)yambul-bul 'kecil-kecil'

Perulangan adjektiva dalam bahasa Ngalum memberikan arti tambahan, yakni orang, benda, atau binatang yang diterangkan itu tak tunggal meskipun dalam kalimat hal itu tidak dinyatakan secara eksplisit. Perhatikan kalimat berikut ini.

(1)adeyape balipeya sikbit-sikbitki pohonnya di sini tinggi-tinggi 'pohon di sini tinggi-tinggi'

(2)tema okwol puka talo-taloki ikan sungai itu besar-besar 'ikan di sungai itu besar-besar'

(3)wanang Oksibil kikora yep-yepki gadis Oksibil perempuan cantikcantik

'gadis Oksibil cantik-cantik'

(4)tena wawka ngorbor-ngorborki anak di sana kurus-kurus 'anak di sana kurus-kurus'

(5)botom kanga kiya yambul-bul bapak babi masih kecil-kecil

'babi bapak masih kecil-kecil'

Pada keempat kalimat di atas, adeyape 'pohon', wanangdi 'gadis', tema 'ikan', tena 'anak', dan kanga 'babi' tidak dinyatakan dalam bentuk ulang. Akan tetapi, karena adjektiva sikbit 'tinggi', talo 'besar', ngorbor 'kurus', yep 'cantik', dan bul 'kecil' diulang sebagian, maka pengertiannya adalah bahwa adeyape balipeya 'pohon di sini', tema okwol puka 'ikan di sungai itu', wanang Oksibil 'gadis Oksibil', tena wawka 'anak di sana', dan botom kanga 'babi bapak' lebih dari satu.

\section{Simpulan}

Berdasarkan hasil analisis di atas dapat diketahui bahwa adjektiva bahasa Ngalum dari segi perilaku semantisnya dibedakan atas adjektiva bertaraf dan adjektiva tak bertaraf. Adjektiva bertaraf bahasa Ngalum dapat dibagi atas (1) adjektiva pemeri sifat, (2) adjektiva ukuran, (3) adjektiva warna, (4) adjektiva waktu, (5) adjektiva jarak, (6) adjektiva sikap batin, dan (7) adjektiva cerapan. Adjektiva tak bertaraf yang terdapat dalam bahasa Ngalum adalah adjektiva bentuk dan adjektiva yang menunjukkan cacat tubuh. Selain itu, adjektiva polimorfemis bahasa Ngalum dibentuk dengan cara perulangan sebagian.

Letak adjektiva bahasa Ngalum dalam kalimat pada umumnya di belakang nomina atau sesudah nomina. Misalnya tena puka melki 'anak itu kuat' (tena 'anak', puka 'itu', dan melki 'kuat'), ade peka kukun 'kayu ini berat' (ade 'kayu', peka 'ini', dan kuku 'berat'), dan abenong walapa ngekneder 'hutan di sana lebat' (abenong 'hutan', walapa 'di sana' dan ngekneder 'lebat').

\section{Daftar Pustaka}

Alwi, Hasan dkk. 2003. Tata Bahasa Baku Bahasa Indonesia. Jakarta: Balai Pustaka.

Badan Pengembangan dan Pembinaan Bahasa, Departemen Pendidikan Nasional. 2013. Bahasa dan Peta Bahasa di Indonesia. Jakarta. 
Chaer, Abdul. 2000. Tata Bahasa Praktis Bahasa Indonesia. Jakarta: PT Rineka Cipta.

Grimer, Barbara F (ed). 2006. Bahasa-Bahasa di Indonesia. Jakarta: SIL International Cabang Indonesia.

Kridalaksana, Harimurti. 2005. Kelas Kata dalam Bahasa Indonesia. Jakarta: PT Gramedia Pustaka Utama.

Ramlan, M. 2005. Sintaksis. Yogyakarta: CV Karyono.

Sudaryanto.1993. Metode dan Aneka Teknik Analisis Bahasa: Pengantar Penelitian Wahana Kebudayaan Secara Linguistis. Yogyakarta: Duta Wacana University Press.

Verhaar, J. W. M. 2010. Asas-Asas Linguistik Umum. Yogyakarta: Gadjah Mada University Press. 